\title{
MEASUREMENT OF PELVIC RETROVERSION DURING HIP FLEXION: EVALUATION WITH ACCELEROMETERS
}

\section{MENSURAÇÃO DE RETROVERSÃO PÉLVICA DURANTE FLEXÃO DO QUADRIL: AVALIAÇÃO COM ACELERÔMETROS}

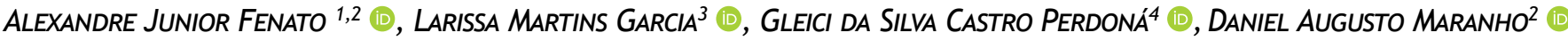 \\ 1. Universidade Tecnológica Federal do Paraná, Electronic Engineering Department, Campus de Ponta Grossa, PR, Brazil. \\ 2. Universidade de São Paulo, Medical School of Ribeirão Preto, Graduate Program in Health Applied Sciences to the Locomotor System, Ribeirão Preto, SP, Brazil. \\ 3. Universidade de São Paulo, Hospital das Clínicas of the Medical School of Ribeirão Preto, Ribeirão Preto, SP, Brazil. \\ 4. Universidade de São Paulo, Medical School of Ribeirão Preto, Social Medicine Department, Ribeirão Preto, SP, Brazil.
}

\section{ABSTRACT}

Objective: To quantify pelvic retroversion during clinical evaluation of hip flexion with accelerometers and to verify the reliability of these sensors to measure hip flexion. Methods: An accelerometer was positioned laterally in the pelvis to measure pelvic retroversion. Another accelerometer was positioned anteriorly on the thigh to evaluate hip flexion amplitude. The evaluations were performed with volunteers in supine position by three raters. For evaluation of pelvic retroversion, the mean $\pm \mathrm{SD}$ (minimum-maximum) was calculated. Reliability of the accelerometer between raters was determined by intraclass correlation coefficients (ICC). The linear correlation coefficient between hip flexion was determined by using goniometer and accelerometer. Results: The mean pelvic retroversion was $7.3^{\circ} \pm 0.93^{\circ}\left(6^{\circ}-11^{\circ}\right)$ in the clinical limit of the hip range of motion, which was $106.25^{\circ} \pm 10.46^{\circ}\left(93^{\circ}-130^{\circ}\right)$. The ICC between two raters were $0.60,0.71$ and 0.74 (goniometer) and 0.46 , 0.71 and 0.83 (accelerometer). The linear correlation between hip flexion measurements with goniometer and accelerometer was 0.87. Conclusion: During clinical evaluation of the final range of hip flexion, there was an associated pelvic movement of approximately $7.3^{\circ}$. Accelerometers have proven to be reliable for measurement of hip flexion. Level of Evidence III, Study of nonconsecutive patients with no gold reference standard applied uniformly.

Keywords: Pelvis. Hip. Articular Arthrometry. Accelerometer.

\section{RESUMO}

Objetivo: Quantificar a retroversão pélvica durante avaliação clínica da flexão do quadril com acelerômetros e verificar a confiabilidade destes sensores para mensurar flexão do quadril. Métodos: Posicionou-se um acelerômetro lateralmente na pelve para mensurar retroversão pélvica. Outro foi posicionado anteriormente sobre a coxa para avaliar flexão do quadril. As avaliações foram realizadas com voluntários, em decúbito dorsal, por três avaliadores. Para avaliação da retroversão pélvica, determinou-se a média $\pm D P$ (mínimo-máximo). Avaliou-se a confiabilidade dos acelerômetros entre avaliadores pelo coeficiente de correlação intraclasse (CCl). Determinou-se o coeficiente de correlação linear entre as mensurações de flexão do quadril com goniômetro e acelerômetro. Resultados: A retroversão pélvica média foi de $7,3^{\circ} \pm 0,93^{\circ}\left(6^{\circ}-11^{\circ}\right)$, mensurada no limite clínico da flexão do quadril, que foi de $106,25^{\circ} \pm 10,46^{\circ}\left(93^{\circ}-130^{\circ}\right)$, ambos com acelerômetro. Os CCl entre dois avaliadores diferentes nas avaliações de flexão do quadril foram de 0,60, 0,71 e 0,74 (goniômetro) e 0,46, 0,71 e 0,83 (acelerômetro). A correlação linear entre as mensurações de flexão do quadril com goniômetro e acelerômetro foi de 0,87. Conclusão: Durante avaliação clínica da amplitude final de flexão do quadril, houve movimentação associada da pelve aproximadamente de $7,3^{\circ}$. Acelerômetros mostraram-se confiáveis para mensuração da flexão do quadril. Nível de evidência III, Estudo de pacientes não consecutivos sem padrão de referência "ouro" aplicado uniformemente.

Descritores: Pelve. Quadril. Goniometria articular. Acelerômetro.

Citation: Fenato AJ, Garcia LM, Perdoná GSC, Maranho DA. Measurement of pelvic retroversion during hip flexion: evaluation with accelerometers. Acta Ortop Bras. [online]. 2020;28(2):69-73. Available from URL: http://www.scielo.br/aob.

\section{INTRODUCTION}

The assessment of hip flexion is essential in semiology for diagnosis, rehabilitation and evolutionary follow-up of joint diseases. ${ }^{1,2}$ The hip flexion, osteoarthrosis limitations ${ }^{3}$, femoroacetabular impingement (FAI) ${ }^{2}$ and degenerative diseases of the lumbar spine are directly related ${ }^{4}$
It is essential that hip flexion assessment are reliable for joint motion to ensure specific treatments, according to the biomechanical conditions of each patient. ${ }^{5}$

Pelvic retroversion occurs during hip flexion ${ }^{6}$, which can start with only $8^{\circ}$ of hip flexion. ${ }^{7}$ If the retroversion of the pelvis is not properly measured, the flexion movement may be overestimated. ${ }^{8}$ Studies that

All authors declare no potential conflict of interest related to this article.

The study was developed at Hospital das Clínicas of Ribeirão Preto Medical School of the Universidade de São Paulo.

Correspondence: Alexandre Junior Fenato. Av. Bandeirantes, 3900, Laboratório de Bioengenharia da FMRP/USP, Ribeirão Preto, Brazil, 14015130. alefenato@usp.br 
passively evaluated healthy hip mobility present variations of up to $24 \%$ in flexion results, but pelvic movement was not analyzed alone..$^{9,10}$ Hip movement assessments in the sagittal plane are complex due to biases related to pelvis control. ${ }^{11}$ Recently, an evaluative study on hip flexion with 100 healthy adults showed that pelvic retroversion of $15^{\circ}$ occurs within the clinical limit of hip flexion amplitude. ${ }^{5}$

The universal goniometer (UG) is often used in hip flexion evaluation ${ }^{12}$, but there may be difficulties during the stabilization of the anatomical segment due to the use of both hands in the handling of the goniometer arms. Furthermore, the alignment of the arms is visual and subjective. ${ }^{13,14}$ New tools have been used in the assessment of joint range of motion to make the process simpler and more accurate, such as: inclinometers ${ }^{15,16}$, smartphone apps ${ }^{17}$, photogrammetry ${ }^{18}$, image tests ${ }^{19}$ and the Inertial Movement Unit (IMU). ${ }^{20}$ Recent studies on the assessment of human gait have shown that IMU - motion sensor typically composed of acceleration transducers (accelerometers), rotation (gyroscopes) and magnetic orientation (magnetometers) -, present accurate results in kinematic knee and hip evaluations. ${ }^{21}$ IMU dispense external references. ${ }^{20}$ In this case, after positioning the sensors, the rater's hands are free, which could enable a more accurate evaluation, including the pelvis monitoring. Quantitative data on pelvis retroversion during hip flexion evaluations are uncommon in the literature, as well as possible effects on the clinical implications of hip flexion oversizing. This study proposes the use of accelerometers to measure pelvic retroversion during clinical evaluations of hip flexion and to evaluate the reliability of these sensors to measure hip flexion movements.

\section{MATERIAL AND METHODS}

This study was approved by the Research Ethics Committee of the Institution with the consent form signed by each volunteer. A total of twenty-three hips (11 right and 12 left) of 12 volunteers (5 men and 7 women) with a mean age of $30 \pm 8$ years and body mass index with a median of $23.7 \mathrm{Kg} / \mathrm{m}^{2}$ (22-27.8) were evaluated. Volunteers were healthy people with no complaints of pain, no diagnosis of disease nor hip surgery, except for a volunteer who complained of right hip pain without a defined diagnosis. He was evaluated only on the left side. Measurements were performed by three different raters - an orthopedic surgeon with 12 years of experience in hip preserving surgery, a physical therapist trained in hip physical evaluation with 10 years of experience, and an engineer involved in the development of the system with accelerometers, who received specific training for hip goniometry. A training session between raters was performed before the collection, to standardize the evaluation and the positioning of the sensors. Volunteers were asked to wear adequate clothing and to provide no resistance to performing movements. Initially, the hip flexion amplitude was evaluated in supine horizontal position by digital goniometry ${ }^{22,23}$, it was followed by the evaluation of hip flexion amplitude and pelvis retroversion by the system with accelerometers. Each rater examined the hips independently, without knowing the results of the other raters. The amplitude of passive flexion was measured until the rater's perception of pelvic motion onset.

Goniometry was performed with a digital device of two long arms (Brand: Vktech; Model: X15-33) (Figure 1).

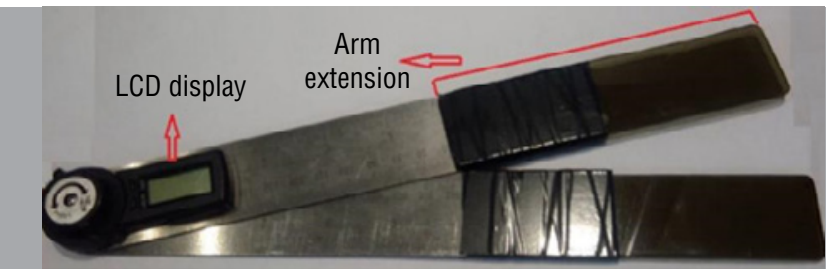

Figure 1. Digital goniometer of long arms
The system of electronic evaluation by accelerometers was based on the Arduino platform (system with low-cost data acquisition and free software) and it was composed of two IMU (Movement Proccessing Unit [MPU] 6050 from Invensense), Arduino UNO acquisition plate and secondary components for connections and sampling of the data (Figure 2).

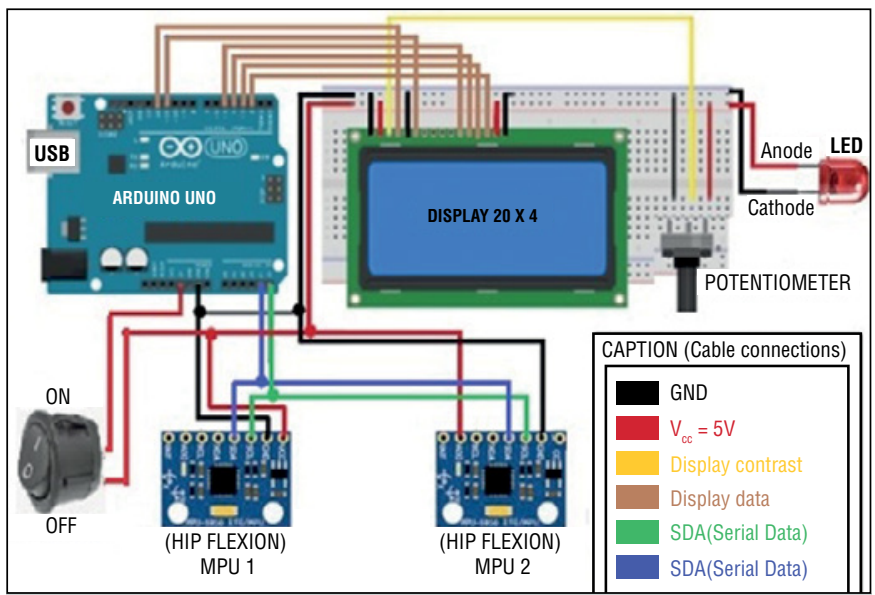

Figure 2. Electronic system for hip flexion and pelvic retroversion evaluation .

The MPUs-6050 were placed inside acrylic casings (parallelepiped format). The sensor circuit was electrically and mechanically isolated and it caused no discomfort to volunteers. Each MPU-6050 has a triaxial accelerometer (responsible for measurements), whose axes $(x, y, z)$ were fixed parallel to the faces of the casing, with external identification of the respective orientations (Figure 3 ). The system worked with electrical voltages up to 5 volts, which did not provide risk of electric shocks.

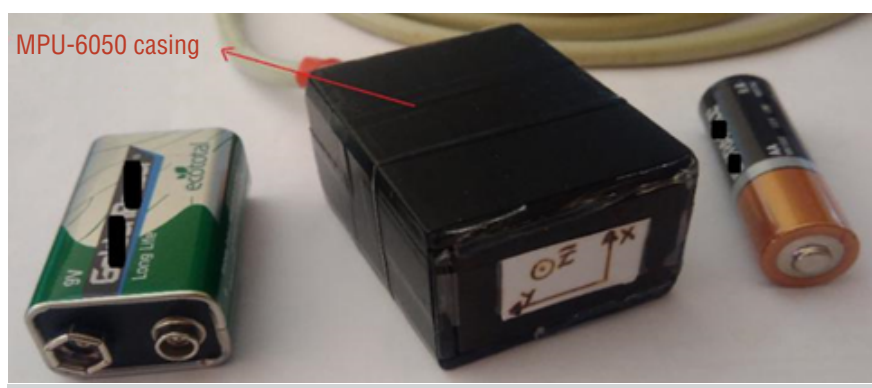

Figure 3. Casing of the hip flexion accelerometer estimator (similar to pelvic retroversion estimator) with identification of the orientations of the accelerometer axes for guidance during positioning. The batteries are for dimensional references.

The accelerometer responsible for measuring hip flexion was positioned with elastic and Velcro-like in the distal third of the thigh. The accelerometer - adjusted to measure the pelvic retroversion - was fixed laterally at the level of the anterior superior iliac spines, on the skin and under elastic firmly tied up around the pelvis (Figure 4). Both measured movements occur in the sagittal anatomical plane, with accelerometers configured to measure the variations in the gravitational acceleration (g). The three piezoelectric "membranes," spatial and orthogonally arranged among each other in triaxial accelerometers, varying their deformations and responses according to the vector " $g$ " (module, direction and gravitational acceleration direction). ${ }^{23}$

Acta Ortop Bras. 2020;28(2):69-73 


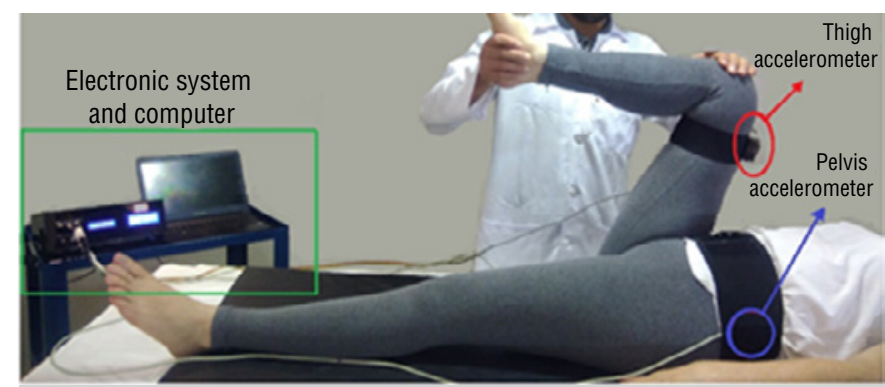

Figure 4. Positioning of pelvic accelerometers (pelvic retroversion estimator) and thigh accelerometer (hip flexion estimator).

The thigh accelerometer was placed with the "x"axis aligned to the craniocaudal axis, "y" axis on the transversal axis and the " $z$ " axis on the anterior posterior axis, then " $x$," " $y$," and " $z$ " axes are orthogonal to each other. The axes " $x$ " and " $z$ " vary their inclination in the sagittal plane and in relation to the vector " $g$," during hip flexion movements (Figure 5). The linearity of the sensor response (proportionality relationship between deformation of piezoelectric material and measured angle) is desirable in this application and it occurs as more aligned (parallel) the axis responsible for measurement is to the vector "g." As the flexion amplitudes usually range between $90^{\circ}$ and $120^{\circ}, 24$ the " $z$ " axis was more appropriate. At $90^{\circ}$, for example, the accelerometer will measure the maximum value, because the piezoelectric material will present the greatest deformation. In the initial position (extended hip), the "z" axis has direction opposite to the vector "g." The result is negative (deformation in the opposite direction to the " $z$ " axis) for angles less than $90^{\circ}$ and the result is positive (deformation and vector " $g$ " in the same direction) for angles greater than $90^{\circ}$ (Figure 6).

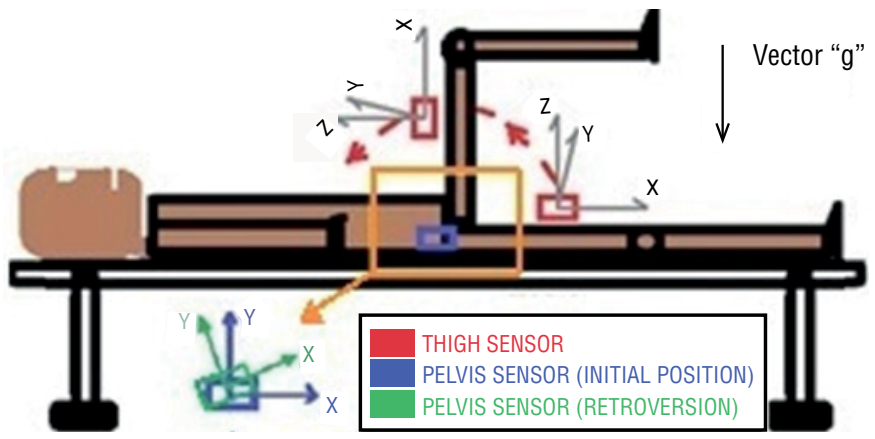

Figure 5. Lateral view of the estimator axes positioning of the pelvis and hip accelerometers. Orange rectangle: magnification of the " $x$ " and " $y$ " axes of the pelvis sensor in the initial position.

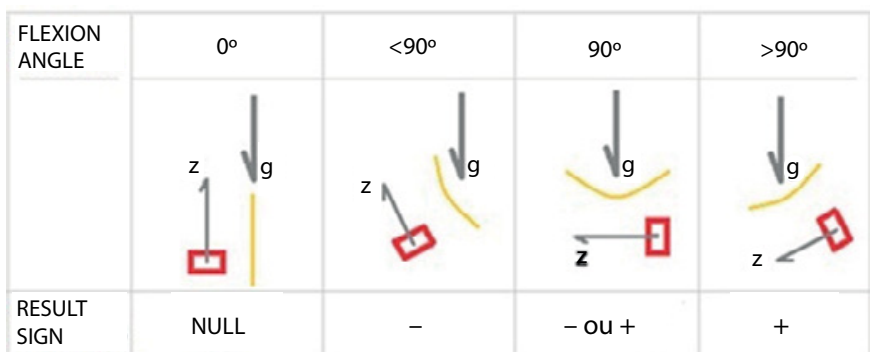

Figure 6. Deformations of the piezoelectric material corresponding to the variation of the vector " $g$ " position.

The determination of the axis responsible for measuring pelvic retroversion was based on the same criteria used to choose the " $z$ " axis of the thigh accelerometer, but with positioning of the " $x$ " and " $y$ " axes dependent on the inclination in the sagittal plane related to the vector " $g$." The " $x$ " axis was chosen as responsible for the retroversion measurements, because as the inclination of the axes presents small variations during this movement, the " $y$ " axis always remains close to the parallel position in relation to the " $g$ " vector, where the results are outside the linear accelerometer response range. The " $\mathrm{z}$ " (hip) and " $x$ " (pelvis) axes chosen presents average standard error for angular measurement of $1.26^{\circ}$ and $0.11^{\circ}$, respectively. The standard error was determined through the quotient of the standard deviation by the square root of the sample size. The estimator axes evaluated only inclination variations in the sagittal plane. During hip flexion evaluations, simultaneous movements (abduction or induction and internal or external rotation) of small amplitude may occur, which do not affect measurements in the sagittal plane. The results of the evaluations using the goniometer and accelerometers were noted in a specific form. The statistical analysis of the data was assisted by the software RCran (R Development Core Team, R: A Language and Environment for Statistical Computing). The mean \pm standard deviation (minimum and maximum value) of the results related to pelvic retroversion measurements by the three raters (69 samples) were determined. Fixed hip flexion angles (flexing angle of the pelvic retroversion subtracted of the hip angle) were estimated. The behavior of hip flexion angles was observed by a box plot graph, before (with goniometer) and after deductions from pelvis movements (with accelerometers), for the complete sample (data from the three raters). The inter-rater ICCs (for the three possible combinations of two raters) were calculated for goniometer and accelerometer to compare the measurements among raters. Pearson's linear correlation coefficient (r) was determined between hip flexion measurements with goniometer and accelerometer (without pelvic retroversion deductions).

\section{RESULTS}

The values (mean \pm standard deviation [minimum-maximum]) of hip flexion (goniometer), hip flexion (accelerometer), pelvic retroversion (accelerometer) and hip flexion with deduction of pelvic retroversion (accelerometers) were, respectively: $106.83^{\circ} \pm 8.91^{\circ}\left(92^{\circ}-129^{\circ}\right)$, $106.25^{\circ} \pm 10.45^{\circ}\left(93^{\circ}-130^{\circ}\right), 7.30^{\circ} \pm 0.93^{\circ}\left(6^{\circ}-11^{\circ}\right)$ and $98.94^{\circ} \pm 10.27^{\circ}$ $\left(87^{\circ}-122^{\circ}\right)$. Boxplot graphs compared the behavior between hip flexion measured with goniometer and the hip flexion with deduction of pelvic retroversion measured by accelerometers (Figure 7).

The ICC estimated between two raters presented better results between physical therapist and orthopedist, for both measurement tools (Table 1). The linear correlation coefficient $(r)$ between hip flexion measurements with goniometer and accelerometer was $87 \%(\mathrm{Cl}=95 \%$ and $\mathrm{p}<0.0001)$ (Figure 8$)$.

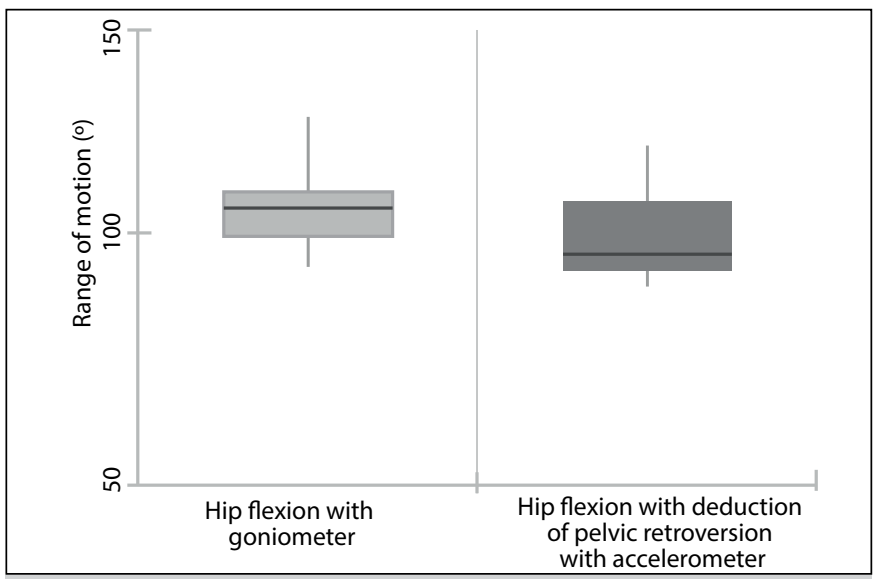

Figure 7. Box plot to compare hip flexion before (with goniometer) and after pelvic retroversion deduction (with accelerometers). 
Table 1. Correlation coefficients between two different raters.

\begin{tabular}{c|c|c|c}
\hline & ICC $_{\text {goniometer }}$ & $95 \%=\mathbf{C l}$ & ICC $_{\text {accelerometer }}$ \\
\hline Rater 1 vs. Rater 2 & 0.598 & $-0.313-0.865$ & 0.461 \\
\hline Rater 1 vs. Rater 3 & 0.714 & $0.024-0.898$ & $0.299-0.78$ \\
\hline Rater 2 vs. Rater 3 & 0.738 & $0.392-0.888$ & 0.711 \\
\hline
\end{tabular}

Rater 1: engineer; Rater 2: hip specialist; Rater 3: Physical therapist; ICC: intraclass correlation coefficient; Cl: confidence interval.

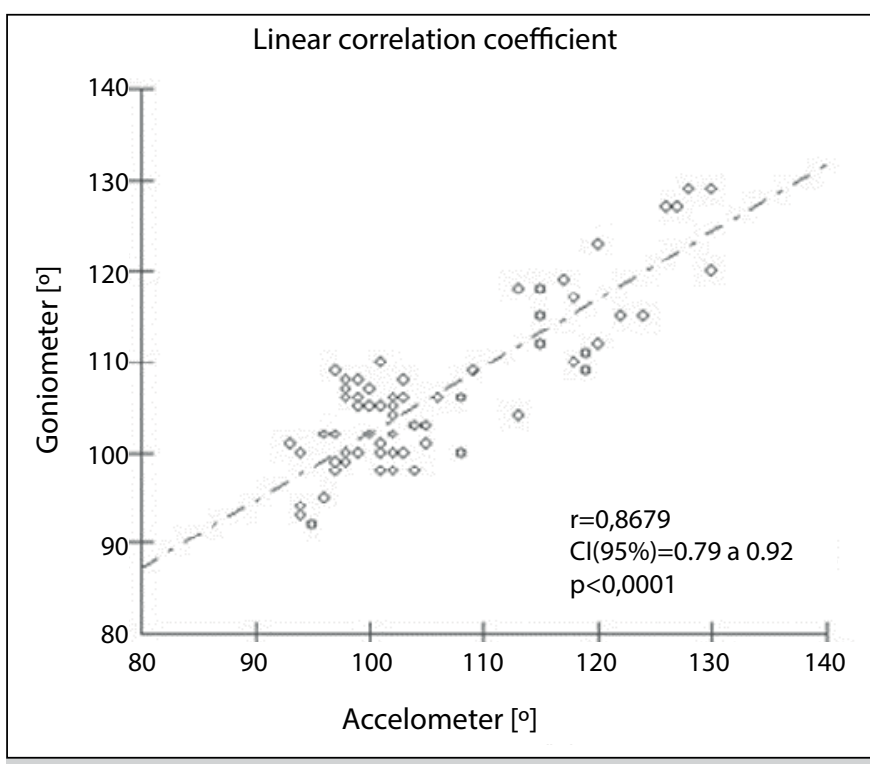

Figure 8. Graph of the linear correlation between hip flexion measurements with goniometer and accelerometer (no deductions from pelvic movements).

\section{DISCUSSION}

Hip flexion assessment is part of the classical semiology for arthrosis diagnostic ${ }^{2}$, femoroacetabular impingement ${ }^{3}$, and lumbar dysfunctions ${ }^{4}$, in addition to specific research protocols. The more reliable the clinical interpretation of joint mobility, the more specific and effective will be the performance of the health professional. In hip flexion assessments, it is suggested the use of one hand under the pelvis to stabilize and to monitor the onset of the pelvic movement. ${ }^{25}$ However, the goniometer requires both hands of the rater to be used, which hinders pelvis monitoring, a factor that implies probable overestimation of hip flexion amplitude. ${ }^{21-28}$ This study presented hip flexion of approximately $107^{\circ}$ with goniometer and $106^{\circ}$ with accelerometer. Although the UG is considered a gold standard in evaluations of joint range of motion, it presents significant differences for hip flexion $\left(113^{\circ}-141^{\circ}\right) . .^{10,16-19}$ New measurement instruments such as accelerometers, which do not rely on external references, would enable hip assessments with pelvic monitoring in a simple way. This study measured pelvis retroversion during hip flexion evaluations by accelerometers and obtained an average result near to $7.3^{\circ}$, in the sample evaluated. Hip flexion measurements performed with accelerometer and goniometer showed a strong linear correlation $(r=0.87)$. The accelerometers were reliable in the measurements of hip flexion (combined: hip plus pelvis). In most analyses, the results showed substantial or optimal inter-rater agreement (ICC > 0.60). ${ }^{26}$ The use of accelerometers in both measurements (flexion and retroversion) proved to be simple and fast. The results regarding the pelvis retroversion increase information to the health professional, supporting the correct interpretations about the mobility of the hip joint. Clinical evaluations of hip flexion amplitude with accelerometers have the potential advantage of deducing pelvic retroversion.
Studies correlating the measurements of joint range of motion between goniometer and other instrument (inclinometers ${ }^{15,16}$, smartphones $^{17}$, imaging exams ${ }^{19}$, and $\mathrm{IMU}^{20}$ ) have shown good results. With increasing technological advances in electronic and computer instrumentation, new devices and techniques are continuously available, with a tendency to improve the accuracy and versatility of the new procedures. In 2015, a study obtained excellent results in hip flexion amplitude evaluations in 20 volunteers, when it compared the measurements performed by inclinometer $(I C C=0.94)$ and smartphone (ICC $=0.92$ ) with 3DMA (Three Dimensional Motion Analysis)..$^{11}$ The high versatility and low cost of accelerometers have supported its progressive use in human gait assessments, energy expenditure monitoring and various applications in many sports. ${ }^{20,21}$ The good results of our research corroborate with recent studies assessing the reliability of accelerometers in human movements..$^{20,21}$ The results presented better agreements among the raters of the field of health, especially the lower limits of the confidence interval (Table 1). A possible interpretation of this episode is due to the small experience of the first examiner (engineer) in executing the movement. Pelvic retroversion begins with approximately $8^{\circ}$ of hip flexion and this movement is extremely complex to monitor and to quantify without technological assistance. ${ }^{7}$ If the retroversion of the pelvis is not considered, hip flexion can be overestimated, making the clinical interpretation inconsistent with the real mobility of the joint. In patients with $\mathrm{FAl}$, during the impingement test (combination of flexion, adduction and internal rotation of the hip), the range of motions are visually assessed and vary with the combination of pelvic movements. ${ }^{2}$ Without deduction of pelvic movements, patients who present normal evaluation for hip flexion may receive the FAI characteristic by lumbar compensation, which may be associated with degenerative changes in the spine. ${ }^{4}$ Pelvic retroversion measured in this study may be clinically important in these cases (FAl and lumbar problems) and extremely useful in decision-threshold circumstances about total hip arthroplasty and positioning guidelines of surgical prostheses. The pair of box plot graphs (Figure 7) showed reductions in median, quartiles, maximum and minimum values of the amplitudes of results of the hip flexion with deduction of pelvic retroversion (accelerometers) in relation to hip flexion without retroversion deduction (goniometer) The same graph (Figure 7) showed greater dispersion (variability) of hip flexion after deduction of pelvic movements. Several studies radiographically evaluated the spinopelvic alignment and inclination of the pelvis in the sagittal plane, with a strong linear correlation between the dimensions evaluated of the obturator foramen and the spinopelvic alignment. However, few studies quantified pelvic movements by the method ${ }^{27}$ A study composed of 101 preoperative patients of total hip arthroplasty measured - by computed tomography through the obturator foramen - the pelvic inclination in the sagittal plane and obtained $5^{\circ}$ (degrees) of pelvic anteversion in the supine position, $3^{\circ}$ in the upright vertical position and $29^{\circ}$ pelvic retroversion with the patients seated. ${ }^{28}$ In the aforementioned study, most patients had advanced arthrosis ${ }^{28}$, which makes it impossible to use the results as parameters in researches with healthy people. Other studies have used the palpation method to identify anterior and posterior reference points of the pelvis for inclinometer fixation and pelvic anteversion measurement, whose values varied $\left(3^{\circ}\right.$ to $\left.10.3^{\circ}\right) \cdot{ }^{27,29}$ 
In 2018, a study with a purpose similar to our research, measured with inclinometer the retroversion of the pelvis ( $15^{\circ}$ on average) during hip flexion. At first, this evaluation occurred with patients in upright vertical position to measure pelvic anteversion (hip in neutral position). Then, in a supine position, for pelvic retroversion evaluation (at the physiological limit of flexion movement). The sum of the two results composed the total pelvic retroversion. ${ }^{5}$ Pelvic retroversion amplitude found in our study is lower $\left(7.3^{\circ}\right)$, compared to those found with inclinometer in $2018\left(15^{\circ}\right)^{5}$, justifiable differences due to the different evaluation protocols, instruments and experience of raters, especially in relation to pelvic monitoring. The hip flexion values found were also greater in the inclinometer study $\left(116^{\circ}\right)$, greater in $10^{\circ}$ compared with this study $\left(106^{\circ}\right)$. Part of this difference probably occurred due to the different criteria regarding the final limits of movement, or variations between the populations studied. The closer to the clinical limits of flexion, the greater the tendency to occur retroversion of the pelvis, possibly as a response to the ligament and musculotendinous limits as well as to the proximity of the proximal region of the femur with the acetabular notch.

This study presented several limitations. One of the main limitations refers to the possibility of relative movement of the accelerometer positioned in the pelvis in relation to the skin and the pelvis. This factor could imply errors in the measurements. No study was found evaluating the relative movement between pelvis and accelerometer. Another limitation refers to the lack of imaging exams, which would enable comparative evaluations, raising the reliability of the study and minimizing the hypothesis of possible evaluations in hips with pathological limitations, which could not be separated in the results. Furthermore, during the study sampling biases occurred, reducing the representativeness of the study: (a) small sample size, which did not enable to correlate variables such as sex and age group; (b) selection of volunteers for convenience. Despite the biases presented, the accelerometer has shown itself as a functional and reliable tool for semiology measurements of hip flexion and according to the positioning methodology presented, the accelerometer has the potential to measure the movements of pelvic retroversion

\section{CONCLUSION}

The pelvic retroversion range in this study presented an approximate mean value of $7.3^{\circ}$. In the sample assessed, the accelerometers were reliable in hip flexion evaluations.

\section{ACKNOWLEDGMENTS}

This study was funded by the Coordination for the Improvement of Higher Education Personnel - Brazil (Capes) - Funding code 001.

AUTHORS' CONTRIBUTIONS: Each author contributed individually and significantly to the development of this article: AJF and DAM actively participated in the development of the accelerometer system and were field raters during the research; LMG was a field rater during the study; GSCP contributed significantly with statistical analysis of the work. All authors contributed throughout the intellectual concept of the article and in the preparing of the manuscript. All authors agree to be held accountable for all aspects of the work, in order to ensure that any issue related to the integrity or accuracy of any of their parties is properly investigated and resolved.

\section{REFERENCES}

1. Yuan BJ, Bartelt RB, Levy BA, Bond JR, Trousdale RT, Sierra RJ. Decreased range of motion is associated with structural hip deformity in asymptomatic adolescent athletes. Am J Sports Med. 2013;41(7):1519-25.

2. Diamond LE, Dobson FL, Bennell KL, Wrigley TV, Hodges, PW, Hinman RS. Physical impairments and activity limitations in people with femoroacetabular impingement: a systematic review. Br J Sports Med. 2015;49(4):230-42.

3. Holla JF, van der Leeden M, Roorda LD, Bierma-Zeinstra SM, Damen J, Dekker $J$, Steultjens MP. Diagnostic accuracy of range of motion measurements in early symptomatic hip and/or knee osteoarthritis. Arthritis Care Res (Hoboken). 2012;64(1):59-65

4. Reiman MP, Weisbach PC, Glynn PE. The hips influence on low back pain: a distal link to a proximal problem. J Sport Rehab. 2009;18(1):24-32.

5. Beneck GJ, Selkowitz DM, Janzen DS, Malecha E, Tiemeyer BR. The influence of pelvic rotation on clinical measurements of hip flexion and extension range of motion across sex and age. Physical Therapy in Sport. 2018;30:1-7.

6. Ahlbaeck SO, Lindahl O. Sagittal mobility of the hip-joint. Acta Orthop Scandinav. 1964;34:310-22

7. Bohannon RW, Gajdosik RL, LeVeau BF. Relationship of pelvic and thigh motions during unilateral and bilateral hip flexion. Phys Ther. 1985;65(10): 1501-04

8. Kamath BJ, Saraswati V, Bansal A, Pai V. Clinical evaluation of hip joint in sagittal plane using pelvifemoral angle. J Clin Orthop Trauma. 2013;4(4):171-3.

9. Boone DC, Azen SP. Normal range of motion of joints in male subjects. J Bone Joint Surg Am. 1979;61(5):756-9.

10. Roach KE, Miles TP. Normal hip and knee active range of motion: the relationship to age. Phys Ther. 1991;71(9):656-65.

11. Kuo YL, Tully EA, Galea MP. Lumbofemoral rhythm during active hip flexion in standing in healthy older adults. Man Ther. 2010;15(1):88-92.

12. Poulsen E, Christensen HW, Penny JO, Overgaard S, Vach W, Hartvigsen J. Reproducibility of range of motion and muscle strength measurements in patients with hip osteoarthritis: an inter-rater study. BMC Musculoskelet Disord. 2012;6(13):242.

13. Torresman, A. Reprodutibilidade inter e intraavaliador na avaliação funcional do quadril [dissertação]. Porto Alegre: Univ Fed Rio Grande do Sul; 2017.

14. Yazdifar M, Yazdifar M. Evaluating the hip range of motion using the goniometer, the nintendo Wii-mote and video tracking methods. European Scientific Journal. 2015;11(21):19-37.

15. Clapis PA, Davis SM, Davis RO. Reliability of inclinometer and goniometric measurements of hip extension flexibility using the modified Thomas test. Physiother Theory Pract. 2008;24(2):135-41.
16. Krause DA, Hollman JH, Krych AJ, Kalisvaart MM, BLevy BA. Reliability of hip internal rotation range of motion measurement using a digital inclinometer. Knee Surg Sports Traumatol Arthrosc. 2015;23:2562-7.

17. Charltona PC, Mentiplaya BF, Puab Y-H, Clark RA. Reliability and concurrent validity of a Smartphone, bubble inclinometer and motion analysis system for measurement of hip joint range of motion. J Sci Med Sport. 2015;18(3):262-7.

18. Marques AP, Marcolan JNO, Prado JNN, Burke TN, Ferreira EAG. Inter- and intra-rater reliability of computerized photogrammetry and universal goniometer in the measurement of hip flexion and abduction. Fisioter Pesqui. 2017;24(1):22-8

19. Miki H, Yamanashi W, Nishii T, Sato Y, Yoshikawa H, Sugano N. Anatomic hip range of motion after implantation during total hip arthroplasty as measured by a navigation system. J Arthroplasty. 2007;22(7):946-52.

20. Luinge HJ, Veltink PH. Inclination measurement of human movement using a 3-D accelerometer with autocalibration. IEEE. 2004;12:112-21.

21. Alonge F, Cucco E, D'Ippolito F, Pulizzotto A. The use of accelerometers and gyroscopes to estimate hip and knee angles on gait analysis. Sensors. 2014; $14: 8430-46$

22. American Academy of Orthopaedic Surgeons. Joint motion method of measuring and recording. Chicago; 1965.

23. Gupalov V, Kukaev A, Shevchenko S, Shalymov E, Venediktov V. Physical principles of a piezo accelerometer sensitive to a nearly constant signal. Sensors (Basel). 2018;18(10)3258.

24. Svenningsen S, Terjesen T, Auflem M, Berg, V. Hip motion related to age and sex. Acta Orthopaedica. 1989;60(1):97-100

25. Norkin CC, White DJ. Measurement of joint motion: a guide to goniometry. 5th ed. Philadelphia: F.A. Davis Company.

26. Landis JR, Koch GG. The measurement of observer agreement for categorical data. Biometrics. 1977;33(1):159-74.

27. Quantification of pelvic tilt and rotation by width/ height ratio of obturator foramina on anteroposterior radiographs. Hip Int. 2016;26(5):462-7.

28. Nishihara S, Sugano N, Nishii T, Ohzono K, Yoshikawa H. Measurements of pelvic flexion angle using three-dimensional computed tomography. Clin Orthop Relat Res. 2003;(411):140-51.

29. Gilliam J, Brunt D, MacMillan M, Kinard RE, Montgomery WJ. Relationship of the pelvic angle to the sacral angle: measurement of clinical reliability and validity. J Orthop Sports Phys Ther.1994;20(4):193-9. 